\title{
Current Approach to Mechanical Valve Obstruction
}

\section{Hüsnü Değirmenci' ${ }^{1 *}$, Eftal Murat Bakırcı ${ }^{1}$, Hikmet Hamur ${ }^{1}$, Arif Arısoy² and Mücahit Tan ${ }^{1}$}

${ }^{1}$ Erzincan Binali Yıldırım University, Faculty of Medicine, Department of Cardiology, Turkey

${ }^{2}$ Gazi Osman Paşa University, Faculty of Medicine, Department of Cardiology, Turkey
Received: 17 December, 2020

Accepted: 28 December, 2020

Published: 29 December, 2020

*Corresponding author: Hüsnü Değirmenci, Erzincan Binali Yıldırım University Faculty of Medicine, Department of Cardiology, Erzincan/Turkey, E-mail: husnudr1982@gmail.com

ORCID: https://orcid.org/0000-0003-0618-7227

Keywords: Mechanical valve; Obstruction; Thrombosis; Pannus; Surgical; Fibrinolytic

https://www.peertechz.com

Check for updates

\section{Abstract}

Although mechanical valve obstruction is rare. It is a rather fatal complication. Pannus and thrombus are common in etiopathogenesis. Multibl imaging methods such as transthoracic echocardiography, transesophageal echocardiography, synefluoroscopy and computed tomography are used for diagnosis. Surgical treatment is performed in the pannus. In thrombosis, fibrinolytic or surgical treatment can be performed. In this article, we presented the current approach to mechanical valve obstruction.

\section{Abbreviations}

MVO: Mechanical Valve Obstruction; PVT: Prosthetic Valve Thrombosis; TTE: Transthoracic Echocardiography; TOE: Transesophageal Echocardiography; CT: Computed Tomography; PV: Peak Velocite; MG: Mean Gradient; DVI: Doppler Velocity Index; EOA: Effective Orifice Area; JK: Contour of the Velocity Jet; AT: Acceleration Time; LVOT: Left Ventricular Outflow Tract; PHT: Pressure Half-Time

\section{Introduction}

Rheumatic valve disease continues to be the most common cause of valve pathologies in developing countries, and mechanical valve replacement continues to be the most commonly used treatment method in these valve pathologies [1]. Mechanical Valve Obstruction (MVO) is one of the most important complications of mechanical valve replacement. MVO is rare but is a feared complication of valve replacement. Mortality risk plays an important role in the fact that MVR is a feared complication and the difficulty in making an etiological diagnosis also plays an important role [2]. In this context, it is the main cause of thrombosis and pannus obstruction. The diagnosis and treatment of these causes are completely different from each other, and misdiagnosis and wrong treatment will lead to life-threatening clinical pictures. For this reason, we decided to write a review called "Current approach to mechanical valve obstruction".

\section{Pathophysiology}

Thrombus, overgrowth of the pannus, or both may be responsible for the pathophysiological process. The incidence of prosthetic valve obstruction has been reported to be $0.3-$ $1.3 \%$ [3]. In a study conducted by Deviri et al., Thrombusrelated obstruction was observed with a rate of $78 \%$, pannusrelated obstruction with $10.7 \%$, and obstruction due to both of them $11.6 \%$ [2]. While pannus is more responsible for aortic valve obstruction, thrombus is more responsible for mitral valve obstruction.

\section{Mechanical valve thrombosis}

Prosthetic Valve Thrombosis (PVT) is a highly fatal complication. Annual PVT incidence has been reported to be $0.03 \%-5.7 \%$ [2]. Thrombus formation is observed in the mechanical valve rather than the bioprosthetic valve. There are obstructive and nonobstructive types. PVT is observed especially in the first postoperative year. Compared to the pannus, thrombus formation appears earlier and as larger masses in imaging methods. Endothelialization begins to develop within a few weeks or months after mechanical valve replacement. During this endothelialization process, clot formation may develop on the endothelium. The thrombus, which is small initially, starts to grow over time. In addition to the endothelialization process, turbulent flow and stasis in the mechanical valve also contribute to thrombus formation. This 
relative stasis and turbulent flow explains why tricuspid valve thrombosis is more than left-sided valve thrombosis and why mitral valve thrombosis is more than aortic valve thrombosis In addition, as the mechanical valve surface area increases, the size of the thrombosis and pannus also increases. The most important reason for this complication is subtherapeutic anticoagulation [4]

\section{Differences of pannus and thrombus}

Less common than thrombus formation is a complication located on mechanical valves. Although the exact mechanism is not known, biological reaction is blamed. However, thrombin production, fibrin deposition, fibroblast proliferation, collagen deposition and neoangiogenesis are blamed in the pathogenesis of pannus. The trigger of the Pannus formation is not clearly understood. It is for this reason that steps towards treatment have been incomplete. Tranforming growth factor beta levels were found to be elevated. Pannus formation can also be a trigger of thrombus formulation [5-7]. The differences between pannus and thrombus are shown in Table $1[2,4]$.

Table 1: Differences between pannus and thrombus.

\begin{tabular}{|c|c|c|}
\hline $\begin{array}{c}\text { Parameters } \\
\text { Time to occur after } \\
\text { valve replacement }\end{array}$ & Pannus & Thrombosis \\
\hline $\begin{array}{c}\text { The onset of symptoms } \\
\text { Relationship } \\
\text { with suboptimal } \\
\text { anticoagulation }\end{array}$ & $\begin{array}{c}\text { Progressive/ } \\
\text { subclinical }\end{array}$ & Sudden/subclinical \\
\hline $\begin{array}{c}\text { The total mass volume } \\
\text { and area }\end{array}$ & Less & More \\
\hline $\begin{array}{c}\text { Lesion density } \\
\text { Localization }\end{array}$ & $\begin{array}{c}\text { Less } \\
\text { ventricular } \\
\text { surface }\end{array}$ & $\begin{array}{c}\text { On the aortic surface in the aortic valve / } \\
\text { On the atrial surface in the mitral valve. }\end{array}$ \\
\hline
\end{tabular}

\begin{tabular}{|c|c|c|}
$\begin{array}{c}\text { Restriction of valve } \\
\text { movement }\end{array}$ & Less & More \\
$\begin{array}{c}\text { Soft ultrasound } \\
\text { intensity }\end{array}$ & Less & More \\
\hline $\begin{array}{c}\text { Ultrasound } \\
\text { videointensity ratio }\end{array}$ & More & Less \\
\hline
\end{tabular}

\section{Diagnosis}

The clinical picture can range from shortness of breath to loss of strength in the extremity secondary to thromboembolism. Although the clinical picture supports mechanical valve obstruction, direct imaging methods have an important place in the diagnosis of obstruction to reveal different etiologies. The significant increase in transvalvular gradient in Doppler echocardiography provides important information. Transthoracic Echocardiography (TTE), Transesophageal Echocardiography (TOE), synfluoroscopy and Computed Tomography (CT) have an important role in making an accurate diagnosis and guiding treatment [8]. It is important to distinguish thrombus from pannus as obstruction etiology is important in treatment selection. However, this distinction is not easy at all. In the initial diagnostic evaluation, valvular movements, obstruction and clot burden should be evaluated with TTE. In addition, patient prosthesis mismatch should also be considered.

\section{Transthoracic echocardiography}

While evaluating aortic mechanical valve obstruction [8], we look at certain parameters in Doppler echocardiography. These parameters include Peak Velocity (PV), Mean Gradient (MG), Doppler Velocity Index (DVI), Effective Orifice Area (EOA), contour of the velocity jet on the mechanical valve (JK) and Acceleration Time (AT). PV and MG depend on the left ventricular function. Left Ventricular Outflow Tract (LVOT) velocity is measured with $\mathrm{PW}$ doppler; aortic valve $\mathrm{PV}$ is measured with CW doppler. DVI is the ratio of LVOT velocity / aortic valve PV. Aortic valve MG, AT and JK are measured with CW doppler. EOA; LVOT diameter ${ }^{2} \mathrm{x}$ LVOT velocity time integral / aortic valve velocity time integral is determined by the formula. This formula is known as the continuity equation. According to these parameters, we can evaluate the aortic mechanical valve under three headings: normal mechanical valve, possible stenotic mechanical valve, and important stenotic mechanical valve. Table 2 shows the evaluation of the aortic mechanical valve by Doppler echocardiography [6]. In case of concurrent aortic insufficiency, PV and MV are significantly affected. If the aortic mechanical valve is to be evaluated with Doppler echocardiography parameters, the stroke volume should be normal or close to normal (50-70 $\mathrm{ml})$.

When evaluating mitral valve obstruction [8], we look at PV, MG, ratio of prosthetic valve PV to LVOT velocity, EOA and Pressure Half-Time (PHT). These values may be affected by conditions such as increased heart rate, increased flow, patient prosthesis incompatibility. Table 3 shows the evaluation of the mitral mechanical valve by Doppler echocardiography [6].

Table 2: The evaluation of the aortic mechanical valve by Doppler echocardiography.

\begin{tabular}{|c|c|c|c|}
\hline Parameters & Normal & Possible Stenosis & $\begin{array}{c}\text { Important } \\
\text { Stenosis }\end{array}$ \\
\hline Peak velocite $(\mathrm{m} / \mathrm{s})$ & $<3$ & $3-4$ & $4<$ \\
\hline Mean Gradient $(\mathrm{mmHg})$ & $<20$ & $20-35$ & $35<$ \\
\hline Doppler velocity index & 0.3 ve üzeri & $0.29-0.25$ & $<0.25$ \\
\hline Effective orifice area $\left(\mathrm{cm}^{2}\right)$ & $\begin{array}{c}1.2< \\
\text { Early peak, } \\
\text { triangle }\end{array}$ & $\begin{array}{c}\text { Peak in the middle, } \\
\text { triangle }\end{array}$ & $\begin{array}{c}\text { Round, } \\
\text { symmetrical }\end{array}$ \\
\hline Jet velocity contour & $<80$ & $80-100$ & $100<$ \\
\hline Acceleration time $(\mathrm{ms})$ & $<8.8$ & $100<$ \\
\hline
\end{tabular}

Table 3: The evaluation of the aortic mechanical valve by Doppler echocardiography

\begin{tabular}{|c|c|c|c|}
\hline Parameters & Normal & Possible Stenosis & Important Stenosis \\
\hline Peak velocite $(\mathrm{m} / \mathrm{s})$ & $<1.9$ & $1.9-2.5$ & 2.5 and above \\
\hline Mean Gradient $(\mathrm{mmHg})$ & 5 and below & $6-10$ & $10<$ \\
\hline $\begin{array}{r}\text { VTImitral prosthesis/ } \\
\text { VTI }\end{array}$ & $<2.2$ & $2.2-2.5$ & $2.5<$ \\
\hline $\begin{array}{c}\text { Effect } \\
\text { Prective orifice area }\left(\mathrm{cm}^{2}\right)\end{array}$ & 2 and above & $1-2$ & $<1$ \\
\hline Pressure half-time $(\mathrm{ms})$ & $<130$ & $130-200$ & $200<$ \\
\hline
\end{tabular}

Citation: Değirmenci H, Bakirci EM, Hamur H, Arısoy A, Tan M (2020) Current Approach to Mechanical Valve Obstruction. Glob J Perioperative Med 4(1): 009-013. DOI: https://dx.doi.org/10.17352/g.jpm.000008 
Tricuspid mechanical valve stenosis is considered if PV is 1.7 $\mathrm{m} / \mathrm{s}<$, MG $5<$ and PHT is $230 \mathrm{~ms}$ and above. While evaluating these parameters, the average of 5 cycles is taken due to respiratory variation. Pulmonary mechanical valve obstruction is suspected when valve thickening, immobility, impaired right ventricular function or increased right ventricular systolic pressure and PV $>3 \mathrm{~m} / \mathrm{s}$ [8].

\section{Synfluoroscopy}

Synfluoroscopy plays an important role in imaging the radiopaque valve discs, comparing the opening and closing angles of the valves and detecting the dehiscence [9]. Compared to synfluoroscopy, valve movements, valve structure and hemodynamic parameters are better evaluated in TOE.

\section{Transesophageal echocardiography}

TOE play an important role in diagnosis, especially when TTE is insufficient in determining the difference between prosthetic incompatibility and prosthetic valve obstruction. TOE plays an important role in determining the risk of systemic embolization of the thrombus. If the thrombus area is over $0.85 \mathrm{~cm}^{2}$, the risk of systemic embolism is high. While TTE sensitivity is $75 \%$ in determining prosthetic valve thrombus, its specificity is $64 \%$ [9-11]. After valve replacement, valve function, iatrogenic stenosis, valve regurgitation, left ventricular function, and coronary ostia are evaluated with TOE [12]. 3D transesophageal echocardiography is particularly useful in demonstrating thrombus in mechanical valve obstruction. Transesophageal echocardiography shows a thrombus on the left atrial surface of the mitral mechanical valve (Figure 1). 3D transesophageal echocardiography shows thrombus on the atrial surface of the mitral mechanical valve (Figure 2). 3D transesophageal echocardiography shows thrombus on the atrial surface of the mitral mechanical valve (Figure 3).

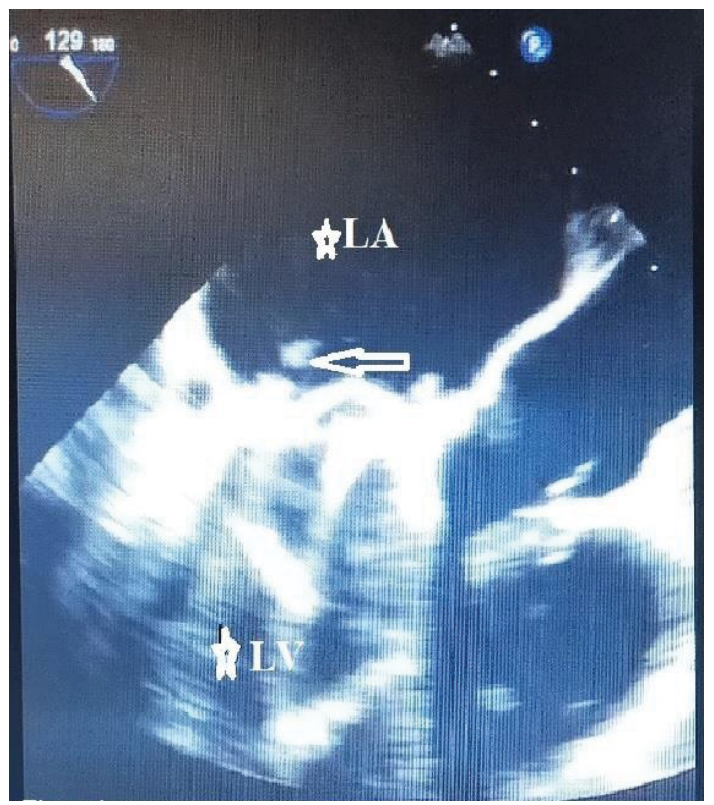

Figure 1: Transesophageal echocardiography shows a thrombus on the left atrial surface of the mitral mechanical valve. LA: left atrium, LV: left ventricle, white arrow: thrombus.

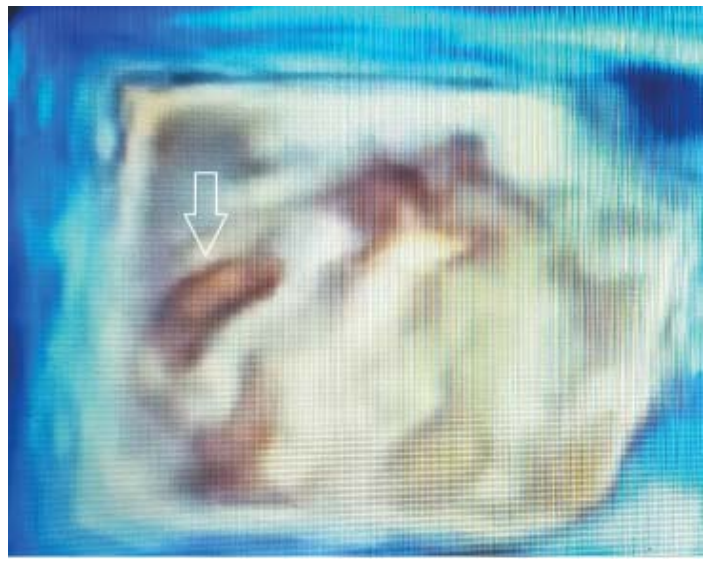

Figure 2: 3D transesophageal echocardiography shows thrombus on the atrial surface of the mitral mechanical valve. White arrow: thrombus.

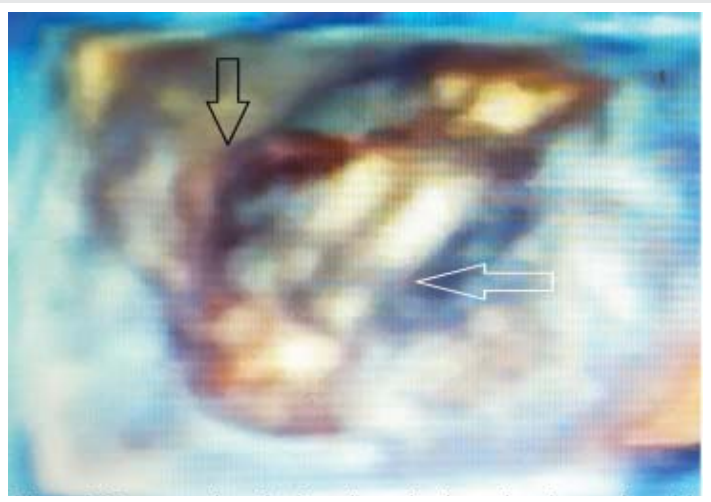

Figure 3: 3D transesophageal echocardiography shows thrombus on the atrial surface of the mitral mechanical valve. White arrow: mitral mechanical valve, black arrow: thrombus.

\section{Computed tomography}

Although it has a limited diagnostic role in prosthetic valve obstruction due to its inadequate evaluation of valve movements and valve hemodynamics, it is a superior examination to echocardiography, especially in the evaluation of pannus in the atrial position. CT is not used in the initial evaluation and is an examination that provides additional information when synfluoroscopy and TOE are insufficient [911]. However, multislice CT plays an important role in detecting abnormalities after valve replacement. Current ECG-gated multislice CT technology, with its superior spatial and adequate temporal resolutions, minimizes beam-hardening and motion artifacts and thus is superior to echocardiography and cardiac Magnetic Resonanse Imaging in terms of spatial resolution in examinations of prosthetic valves [13].

\section{Treatment}

In a suspected mechanical valve thrombosis, evaluation is made primarily by TTE, TOE and fluoroscopy. With these diagnostic methods, it is primarily checked whether thrombosis causes obstruction or not. When evaluated according to the 2017 European valve guideline [14], emergency valve replacement is recommended with a class 1 indication in clinically critical obstructive mechanical thrombosis patients without serious comorbidities. In patients with non-obstructive mechanical

Citation: Değirmenci H, Bakirci EM, Hamur H, Arısoy A, Tan M (2020) Current Approach to Mechanical Valve Obstruction. Glob J Perioperative Med 4(1): 009-013. DOI: 
valve thrombus $>10 \mathrm{~mm}$, which is complicated by an embolic event, surgical intervention with a class $2 \mathrm{a}$ indication is recommended.

Fibrinolytic infusion (10 $\mathrm{mg}$ bolus with unfractionated heparin; $90 \mathrm{mg}$ tissue Plasminogen Activator (tPA) as infusion in 90 minutes or 1500000 units of streptokinase infusion in 60 minutes) can be administered with a class $2 \mathrm{a}$ indication in right-sided mechanical valve thrombosis, in cases where surgery is at high risk or when surgery cannot be performed. In obstructive mechanical valve thrombosis, if the patient is not clinically critical and anticoagulation is insufficient, intravenous unfractionated heparin is administered with aspirin (100 mg and above / daily) or alone and followed. If successful, it is followed up with anticoagulants. If obstructive thrombus has developed in non-critical patients although anticoagulation is sufficient, priority surgery; If surgery is high risk, fibrinolytic is used.

In non-obstructive mechanical valve thrombosis, anticoagulation is optimized and the patient is followed clinically and echocardiographically. If thromboembolism is detected in the follow-up with clinical, cerebral and imaging methods, the size of the thrombus is checked. Priority surgery if the thrombus is $10 \mathrm{~mm}$ or more; If surgery cannot be performed, thrombolytics are applied. If the thrombus is below $10 \mathrm{~mm}$, anticoagulation is optimized and the patient is followed up. If the thrombus persists and recurrent thromboembolism develops, priority surgery; If surgery cannot be performed, fibrinolytic is applied. If the thrombus persists and there is no recurrent thromboembolism, medical monitoring is followed. If there is no thromboembolism in non-obstructive mechanical valve thrombosis and the thrombus size is $10 \mathrm{~mm}$ or more, the anticoagulant is optimized and the patient is followed up. If thromboembolism develops or thrombus persists, first of all surgery; If surgery cannot be performed, fibrinolytic is applied. If the thrombus does not persist or thromboembolism does not develop, medical monitoring is followed. If there is no thromboembolism in non-obstructive mechanical valve thrombosis and the valve thrombus is less than $10 \mathrm{~mm}$, anticoagulant is optimized. If the anticoagulant cannot be optimized, if thromboembolism develops in the followup or thrombus persists, surgery first; If surgery cannot be performed, fibrinolytic is applied.

Let's now consider the 2017 American guide [15]. In the presence of symptoms of valve obstruction, emergency surgery or low-dose fibrinolytic infusion is recommended as a class $1 \mathrm{~b}$ indication in patients with left-sided mechanical valve thrombosis. Our recommendations are based on multiple case reports, single-center studies, multi-center studies, metaanalyzes, and registry reports, rather than a randomized controlled study comparing fibrinolytic therapy and surgical intervention. While the 30 -day mortality rate is $10-15 \%$ with surgical treatment, this rate decreases to $5 \%$ in NYHA 1-2 patients. In fibrinolytic therapy, the 30-day mortality rate is $7 \%$, while the thromboembolism rate is $18 \%$, the bleeding rate is $6 \%$, and the hemodynamic success rate is $75 \%$.

Surgical treatment can be applied, low surgical risk, contraindication to fibrinolytic therapy, current valve thrombosis, NYHA class 4 patients, thrombus over $0.8 \mathrm{~cm} 2$, left atrial thrombus, patients who are currently considered for surgery due to coronary artery disease, in the presence of other valve diseases. Surgery should be considered when the pannus is responsible for etiopathogenesis and the patient desires surgery. In centers where surgery cannot be performed, in cases where there is a high surgical risk, when fibrinolytic is not contraindicated, if there is a first episode of valve thrombosis, in patients with NYHA class 1-3, in patients with a clot size below $0.8 \mathrm{~cm} 2$, in cases where there is no left atrial thrombus, a non-surgical coronary artery If thrombus is seen in the disease and the patient wants medical treatment, fibrinolytic therapy is chosen.

Having an important role in changing the 2017 ACC / AHA guideline recommendations, Özkan et al. different fibrinolytic regimens were compared in the largest-scale TROIA study [16] (182 patients) reported in the literature, and low dose and slow infusion tPA treatment ( $25 \mathrm{mg} 6$ hour infusion) was found to be as successful as other regimens. Although no death was observed in this regimen, PROMETEE study [17] in which an ultra-slow fibrinolytic regimen was applied (25 mg tPA 25 hour infusion) was performed because it is similar to other regimens in terms of major non-fatal complications. In this study, the ultra-slow dose slow infusion regimen was found to be very reliable without losing its effectiveness in patients except for the NYHA class 3-4 patient group. Intracranial bleeding was detected as $0.8 \%$ in the TROIA study, whereas no cases were observed in the PROMETEE study [17].

Pregnant women with mechanical valve thrombosis constitute a special case, and Özkan, et al. Is the largest study conducted on pregnant women so far [18] $25 \mathrm{mg}$ of tissue plasminogen activator was administered as a slow infusion over 6 hours. There were 24 pregnant patients in this group and no fibrinolytic bolus was administered. It has been reported that if necessary, the maximum dose of fibrinolytic can be repeated to $150 \mathrm{mg}$. Placental bleeding and minor bleeding were reported in only 1 patient.

\section{Conclusion}

MVO is a complication with high morbidity and mortality rates. Multidisciplinary team approach is required in this complication. In addition, early diagnosis and early treatment are extremely important in this complication. In these patients, MVO should be suspected in case of shortness of breath, signs of embolism and hemodynamic deterioration. Today, low dose thrombolytic regimens are used frequently and successful results are obtained. Therefore, we recommend the use of lowdose fibrinolytic regimens in patients with high surgical risk and suitable for fibrinolytic regimen.

\section{References}

1. Lung B,Vahanian A (2011) Epidemiology of valvular heart disease in the adult. Nat Rev Cardiol 8: 162-172. Link: https://bit.ly/3hraCFp

2. Dangas GD, Weitz JI, Giustino G, Makkar R, Mehran R (2016) Prosthetic Heart Valve Thrombosis. J Am Coll Cardiol 68: 2670-2689. Link: https://bit.ly/3ptRZU9

Citation: Değirmenci H, Bakirci EM, Hamur H, Arısoy A, Tan M (2020) Current Approach to Mechanical Valve Obstruction. Glob J Perioperative Med 4(1): 009-013. DOI: 
3. Ouazzani JEL, Mouedder F, El Ouafi N, Ismaili N (2020) The Nightmare of Obstructive Mechanical Valve Thrombosis: What is the Optimal Care? Int J Cardiovasc Acad 6: 176-179. Link: https://bit.ly/3aO2Swa

4. Barbetseas J, Nagueh SF, Pitsavos C, Toutouzas PK, Quiñones MA, et al. (1998) Differentiating Thrombus From Pannus Formation in Obstructed Mechanical Prosthetic Valves: An Evaluation of Clinical, Transthoracic and Transesophageal Echocardiographic Parameters. J Am Coll Cardiol 32: 1410 1417. Link: https://bit.ly/2M1ZKCf

5. Lim WY, Lloyd G, Bhattacharyya S (2017) Mechanical and surgical bioprosthetic valve thrombosis. Heart 103: 1934-1941. Link: https://bit.ly/3n060al

6. Salamon J, Munoz-Mendoza J, Liebelt JJ, Taub CC (2015) Mechanical valve obstruction: Review of diagnostic and treatment strategies. World J Cardiol 7 875-881. Link: https://bit.ly/34NRbSm

7. Bonou M, Lampropoulos K, Barbetseas J (2012) Prosthetic heart valve obstruction: thrombolysis or surgical treatment? Eur Heart J Acute Cardiovasc Care 1: 122-127. Link: https://bit.ly/37Tdt6R

8. Zoghbi WA, Chambers JB, Dumesnil JG, Foster E, Gottdiener JS, et al. (2009) Recommendations for evaluation of prosthetic valves with echocardiography and doppler ultrasound: a report From the American Society of Echocardiography's Guidelines and Standards Committee and the Task Force on Prosthetic Valves, developed in conjunction with the American College of Cardiology Cardiovascular Imaging Committee, Cardiac Imaging Committee of the American Heart Association, the European Association of Echocardiography, a registered branch of the European Society of Cardiology, the Japanese Society of Echocardiography and the Canadian Society of Echocardiography, endorsed by the American College of Cardiology Foundation, American Heart Association, European Association of Echocardiography, a registered branch of the European Society of Cardiology, the Japanese Society of Echocardiography, and Canadian Society of Echocardiography. 22: 975-1014. Link: https://bit.ly/3mUHiZd

9. Henderson PJ, Harrison TJ, Wildes DE (2018) Obstruction Alternans": A Rare Presentation of Mechanical Mitral Valve Obstruction. Cardiovascular Imaging Case Reports 2: 244-247. Link: https://bit.ly/3aPOzHc

10. Tanis W, Budde RPJ, van der Bilt IAC, Delemarre B, Hoohenkerk G, et al. (2016) Novel imaging strategies for the detection of prosthetic heart valve obstruction and endocarditis. Neth Heart J 24: 96-107. Link: https://bit.ly/38HtM5R
11. Lancellotti P, Pibarot $P$, Chambers J, Edvardsen T, Delgado V, et al. (2016) Recommendations for the imaging assessment of prosthetic heart valves: a report from the European Association of Cardiovascular Imaging endorsed by the Chinese Society of Echocardiography, the Inter-American Society of Echocardiography, and the Brazilian Department of Cardiovascular Imaging. Eur Heart J Cardiovasc Imaging 17: 589-590. Link: https://bit.ly/3aLxgad

12. Nicoara A, Skubas N, Ad N, Finley A, Hahn RT, et al. (2020) Guidelines for the Use of Transesophageal Echocardiography to Assist with Surgical Decision-Making in the Operating Room: A Surgery-Based Approach From the American Society of Echocardiography in Collaboration with the Society of Cardiovascular Anesthesiologists and the Society of Thoracic Surgeons. J Am Soc Echocardiogr 33: 692-734. Link: https://bit.ly/3nUtTBE

13. Ghersin E, Martinez CA, Singh V, Fishman JE, Macon CJ, et al. (2014) ECG Gated MDCT After Aortic and Mitral Valve Surgery. AJR Am J Roentgeno 203 W596-W604. Link: https://bit.ly/3aMVoJF

14. Baumgartner H, Falk V, Bax JJ, De Bonis M, Hamm C (2017 2017 ESC/EACTS Guidelines for the management of valvular heart disease. European Heart Journal 38: 2739-2791. Link: https://bit.ly/3rs5ICh

15. Nishimura RA, Otto CM, Bonow RO, Carabello BA, Erwin JP, et al. (2017) A Report of the American College of Cardiology/American Heart Association Task Force on Clinical Practice Guidelines. 2017 AHA/ACC Focused Update of the 2014 AHA/ACC Guideline for the Management of Patients With Valvular Heart Disease. J Am Coll Cardiol 70: 252-289. Link: https://bit.ly/2LODEzL

16. Özkan M, Gündüz S, Biteker M, Astarcioglu MA, Çevik C, et al. (2013) Comparison of different TEE-guided thrombolytic regimens for prosthetic valve thrombosis: the TROIA trial. JACC Cardiovasc Imaging 6: 206-216. Link: https://bit.ly/3mSEz2p

17. Guner A, Gunduz S, Gursoy MO, Bayam E, Kalkan S, et al. (2018) The PROMETEE protocol is safe and efficient in patients with prosthetic valve thrombosis. Echocardiography 35: 1487. Link: https://bit.ly/3hmxDta

18. Özkan M, Çakal B, Karakoyun S, Gürsoy OM, Çevik C, et al. (2013) Thrombolytic therapy for the treatment of prosthetic heart valve thrombosis in pregnancy with low-dose, slow infusion of tissue-type plasminogen activator. Circulation 128: 532-540. Link: https://bit.ly/3nVPIWK

\section{Discover a bigger Impact and Visibility of your article publication with} Peertechz Publications

\section{Highlights}

* Signatory publisher of ORCID

- Signatory Publisher of DORA (San Francisco Declaration on Research Assessment)

* Articles archived in worlds' renowned service providers such as Portico, CNKI, AGRIS, TDNet, Base (Bielefeld University Library), CrossRef, Scilit, J-Gate etc.

* Journals indexed in ICMJE, SHERPA/ROMEO, Google Scholar etc.

* OAI-PMH (Open Archives Initiative Protocol for Metadata Harvesting)

* Dedicated Editorial Board for every journal

* Accurate and rapid peer-review process

* Increased citations of published articles through promotions

* Reduced timeline for article publication

Submit your articles and experience a new surge in publication services (https://www.peertechz.com/submission).

Peertechz journals wishes everlasting success in your every endeavours.

Copyright: @ 2020 Değirmenci H, et al. This is an open-access article distributed under the terms of the Creative Commons Attribution License, which permits unrestricted use, distribution, and reproduction in any medium, provided the original author and source are credited.

Citation: Değirmenci H, Bakirci EM, Hamur H, Arısoy A, Tan M (2020) Current Approach to Mechanical Valve Obstruction. Glob J Perioperative Med 4(1): 009-013. DOI: https://dx.doi.org/10.17352/gjpm.000008 